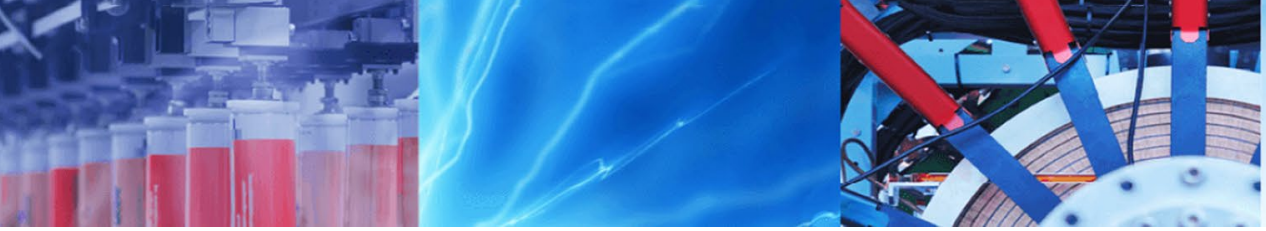

Research Article

\title{
Polymer-coated magnetic nanoparticles for the efficient capture of Mycobacterium tuberculosis (Mtb)
}

\author{
Marica Smit ${ }^{1}$ (D) . Marietjie Lutz ${ }^{1}$ (D)
}

Received: 16 December 2019 / Accepted: 21 August 2020 / Published online: 9 September 2020

(c) Springer Nature Switzerland AG 2020

\begin{abstract}
Modified chitosan and modified poly(styrene-alt-maleic anhydride) (SMA) were synthesized and utilized to coat superparamagnetic magnetite nanoparticles (SPMNs) to act as potential Mycobacterium tuberculosis (Mtb) capturing substrates. Chitosan and SMA were modified to form quaternary derivatives which have the potential to interact with the Mtb cell wall. The nano-substrates were also surface functionalized with a carbohydrate-binding protein, namely Concanavalin $\mathrm{A}$ (Con A), which can bind to the Mtb cell wall. Chitosan coated SPMNs were synthesized by in situ co-precipitating Fe ${ }^{2+}$ and $\mathrm{Fe}^{3+}$ with chitosan followed by further modification. SMA coated SPMNs were synthesized by activating the iron oxide core with 3-aminopropyl(triethoxysilane) followed by further modification. The nano-substrates were evaluated for their affinity and thus capturing capabilities utilizing the mCherry fluorophore tagged bacillus Calmette-Guérin (BCG) strain of Mycobacterium bovis, a live attenuated $M t b$-mimic. Quaternary SMA (SMI-qC ${ }_{12}$ ) revealed the highest overall affinity for BCG-mCherry (through electrostatic and hydrophobic interactions) whereas Con A immobilized chitosan had the highest affinity for the chitosan coated nanoparticles. The SPMNs were coated with three different polymer loadings and a dilution study was performed to determine the limit of detection. The $0.9 \mathrm{~g}$ loaded SMI-qC $\mathrm{C}_{12}$ SPMNs revealed the highest affinity for BCG-mCherry as determined via fluorescence microscopy and transmission electron microscopy.
\end{abstract}

Keywords Iron oxide nanoparticles · Biomaterials · Diagnosis · Chitosan · Poly(styrene-alt-maleic anhydride) · Mycobacterium tuberculosis

\section{Introduction}

Tuberculosis (TB) is one of the three primary povertyrelated infectious diseases which has a high morbidity and mortality rate. Low bacilli yield leads to an ongoing challenge when it comes to the diagnosis and management of childhood TB in developing countries [1]. Mycobacterium tuberculosis $(M t b)$ is an intracellular pathogen that relies on the survival of the microorganism within host cells and is the causative pathogen of tuberculosis. This mode of infection and frequent lack of clinical symptoms hinders detection of the pathogen. Current diagnostic tests are limited due to the fact that it is difficult to detect low populations of bacteria in biological fluids, such as sputum, blood and lymph fluid [2]. A large volume of biological fluid, such as sputum, is needed for a positive diagnosis of TB. Multiple samples need to be collected for such a large volume and this is very difficult, especially in the case of children under six years [3]. If, however, the Mtb can be concentrated within the sample then a smaller amount of biological fluid will be needed for testing. In such a case substrates with an affinity for the pathogen can ideally be used to capture and thus concentrate $M t b$.

Electronic supplementary material The online version of this article (https://doi.org/10.1007/s42452-020-03403-9) contains supplementary material, which is available to authorized users.

Marietjie Lutz, mlutz@sun.ac.za | 1 Department of Chemistry and Polymer Science, Stellenbosch University, Stellenbosch, South Africa. 
Chitosan and poly(styrene-alt-maleic anhydride) (SMA) are examples of polymers that have known affinity for Mtb. Chitosan, a natural polysaccharide, possesses favourable properties, such as antibacterial activity, non-toxicity, biocompatibility and biodegradability [4]. Previous research has shown that the quaternary derivatives of $\mathrm{N}$-alkyl chitosan have even higher bacterial activity when compared to neat chitosan [5]. SMA has good biocompatibility, low toxicity, is biodegradable and is relatively cheap, which makes this compound a good choice as a biological substrate. The reactive anhydride functional groups have the advantage that they have the potential to form quaternary ammonium derivatives of SMA with known Mtb affinity [6]. Both chitosan and SMA have previously shown the ability to facilitate bacterial adhesion via chemical modification. Concanavalin A (Con A), immobilized to chitosan and SMA, is furthermore a well-studied carbohydrate-binding protein and human receptor for the carbohydrate-based structures on the surface of $M t b$, such as mannose. The interaction between these human receptors and mycobacterial mannose have the potential to capture and concentrate Mtb.

Previous research that focussed on the optimization of existing TB test methods involved the synthesis of affinity substrates to enable the capture and concentration of Mtb for improved diagnosis. A study by Cronje reports the synthesis of nanofibers with high affinity for bacillus Calmette-Guérin (BCG), as well as Mtb, by electrospinning poly(styrene-co-maleic anhydride) (SMA) functionalized with a $\mathrm{C}_{12}$ aliphatic quaternary ammonium moiety $[7,8]$. In a similar study by Du Plessis, poly(styrene-alt-maleic anhydride) (SMA) electrospun into nanofibers and functionalized with Con A, captured BCG most effectively due to saccharide binding of the protein. The modification of SMA with aliphatic quaternary ammonium moieties of chain lengths $C_{8}-C_{12}$ also revealed capturing abilities through hydrophobic and ionic interactions [9]. Fortuin investigated the BCG affinity of polymer coated iron oxide and quaternized chitosan nanofibers and found that chitosan coated nanoparticles functionalized with a $C_{12}$ aliphatic quaternary ammonium moiety $\left(\mathrm{CS}-\mathrm{q} \mathrm{C}_{12}\right)$ was the most effective in capturing BCG [10].

This study used FM (fluorescence microscopy) to determine which polymer-and-functional-moiety combination has the highest affinity and thus capturing capability for the bacteria. The polymers investigated are chitosan and poly(styrene-alt-maleic anhydride) (SMA) and the functional moieties Concanavalin $A$ and $C_{12}$ aliphatic quaternary ammonium. The aim of this study was to develop a magnetic, polymer coated $M t b$ capturing substrate to improve the diagnosis of TB (especially with low bacilli yield) by concentrating the bacilli in a sample. These coated magnetic nanoparticles will have the potential to capture the bacilli and remove the concentrated bacteria from the sample in the presence of an external magnetic field.

Superparamagnetic iron oxide nanoparticles (SPIONs) have shown high saturation field and high field irreversibility, which enable the particles to no longer show magnetic interaction after the external magnetic field is removed [11]. This expands the application possibilities of the nanoparticles in controlled magnetism and also gives magnetic properties to larger structures. Biocompatibility and toxicity of SPIONs are important criteria for use in biomedical applications. Biocompatibility is determined by the final size of the particles (including the core), the coatings, the magnetic responsive component (such as, iron, magnetite, cobalt, nickel, neodymium-iron-boron or samarium-cobalt), and the stability at neutral $\mathrm{pH}$. The nanoparticles must have a high magnetization capability to control the movement of the particles in a sample with a magnetic field. Highly magnetic metals such as nickel and cobalt are susceptible to oxidation and toxic and can therefore not be used. Iron oxide particles, such as magnetite $\left(\mathrm{Fe}_{3} \mathrm{O}_{4}\right)$ or its oxidised form maghemite $\left(\gamma-\mathrm{Fe}_{2} \mathrm{O}_{3}\right)$, are most commonly used in biomedical applications [12]. Magnetite was used in this study due to its superparamagnetic properties as well as ease of synthesis via co-precipitation. The surface of these nanoparticles have previously been coated with a polymer for use in biomedical applications [13].

Iron oxide has surface hydroxyl groups that can be used for complex formation with polymer coatings [14]. Polymers such as chitosan have hydroxyl, amino and ether groups that can adhere to the surface of iron oxide nanoparticles via hydrogen bonding. The chitosan coated nanoparticles were synthesized (in situ) via co-precipitation of $\mathrm{Fe}^{2+}, \mathrm{Fe}^{3+}$ and dissolved chitosan. The polymer coating should improve dispersion in solution and thus decrease aggregation [15]. Pristine chitosan forms a shell around the iron oxide core due to polymer chelation. In this study, the outer chitosan coating was functionalized to form quaternized chitosan (Fig. 1a, 1) and Con A immobilized chitosan after the addition of linker molecules (2). The iron oxide core can furthermore be surface activated with 3-aminopropyl(triethoxysilane) (3-APTES) [16]. The amino groups created on the surface of iron oxide via 3-APTES was used in this study to coat with SMA. The reactive maleic anhydride of SMA can easily react with amine groups, creating imide bonds, as seen via Con $A$ immobilization (3). Further functionalization of SMA with 3-(N,N-dimethylamino)-1-propylamine and 1-bromododecane resulted in quaternized SMA (4). Three different polymer loadings were used $(0.1,0.5$ and $0.9 \mathrm{~g}$ polymer per $1 \mathrm{~g}$ iron oxide nanoparticles) to determine the effect of polymer loading. 


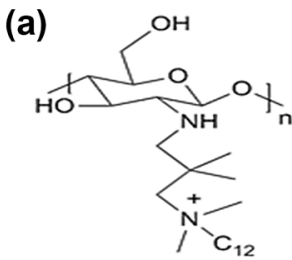

$1\left(\mathrm{CS}-\mathrm{qC} \mathrm{C}_{12}\right)$<smiles>CC(=O)N1C(=O)C(CC(c2ccccc2)C(C)(C)C)C(C(C)(C)C)C1=O</smiles>

3 (SMI-Con A)

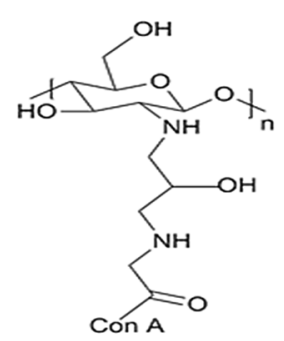

2 (CS-EDC-Con A)<smiles>CC(C)(C)c1ccccc1CC1C2CCCC(C1C(C)(C)C)N2CCC[N+](C)(C)C</smiles>

$4\left(\mathrm{SMI}^{-\mathrm{qC}_{12}}\right)$

(c)<smiles>CC(C)C1C(=O)N(CCCN(C)C)C(=O)C1CC(C)(C)C</smiles><smiles>BrC=CCBr</smiles><smiles>CC(C)(C)CC1C(=O)N(CCC[N+](C)(C)C)C(=O)C1C(=O)c1ccccc1</smiles>

(b)

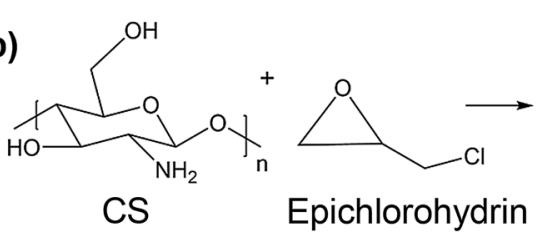

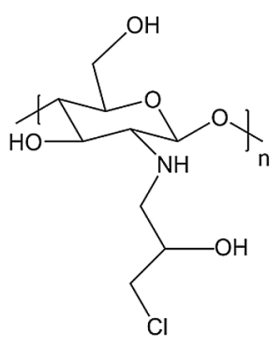<smiles>NCC(=O)O</smiles>

Glycine

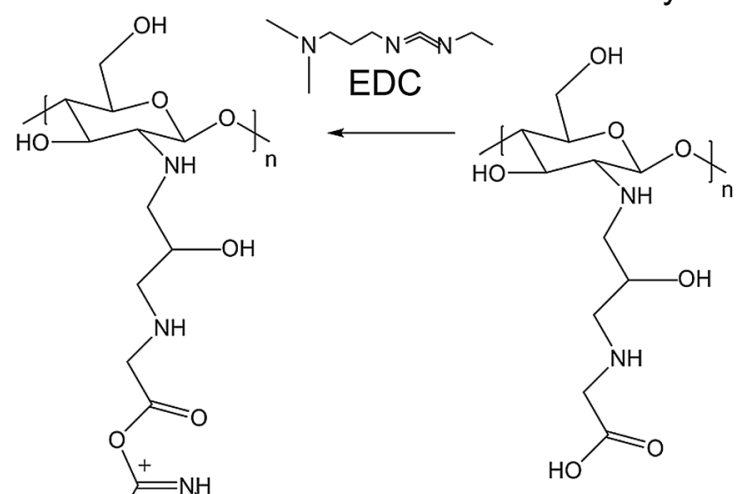

Fig. 1 a Chemical structures of the modified chitosan and SMI compounds, $\mathbf{b}$ synthesis of CS-EDC and $\mathbf{c}$ synthesis of SMI-qC 12

The Mtb capturing capabilities of the polymer coated nanoparticles were evaluated with mCherry fluorophore tagged Bacillus Calmette-Guérin (BCG) at a neutral $\mathrm{pH}$. BCG-mCherry was used as Mtb mimic as it is the live attenuated strain of Mycobacterium bovis and genetically similar to Mtb [17]. Fluorescence microscopy (FM), light microscopy (LM) and transmission electron microscopy (TEM) were used to evaluate the interaction between the polymer coated nanoparticles and BCG-mCherry. The polymer coated nanoparticles were furthermore characterized using attenuated total reflectance Fourier transform infrared spectroscopy (ATRFTIR), powder X-ray diffraction (P-XRD), thermogravimetric analysis (TGA), TEM, the horseradish peroxidase (HRP) enzymatic assay and superconducting quantum interference device (SQUID) magnetometry.

\section{Experimental}

\subsection{Materials}

The following chemicals were used: chitosan (Sigma-Aldrich, Mw = 129 000, DDA 75), acetic acid (Merck, $\geq 97.7 \%), \mathrm{FeCl}_{3} \cdot 6 \mathrm{H}_{2} \mathrm{O}$ (98\%, Sigma-Aldrich), $\mathrm{FeCl}_{2}$ (97\%, Sigma-Aldrich), ammonium hydroxide (25\% in $\mathrm{H}_{2} \mathrm{O}$, Merck), ethanol (Sigma-Aldrich, 99.5\%), glutaraldehyde solution (Sigma-Aldrich, 50 wt $\%$ in $\mathrm{H}_{2} \mathrm{O}$ ), epichlorohydrin (Aldrich, 99\%), glycine (Saarchem, 99\%), 1,4-dioxane (Sigma-Aldrich, $\geq 99 \%$ ), sodium hydroxide pellets (Merck, $\geq 97 \%$ ), acetone (Sigma-Aldrich, 99.5\%), $N$-(3-dimethylaminopropyl)- $N$ '-ethylcarbodiimide hydrochloride (EDC) (Sigma-Aldrich, $\geq 99 \%$ ), Concanavalin A 
from Canavalia ensiformis (Jack bean) Type VI (Sigma Aldrich), $\mathrm{CaCl}_{2}$ (Merck, 98\%), $\mathrm{MnCl}_{2}$ (Sigma Aldrich, beads 99\%), $\mathrm{NaCl}$ (Scienceworld, 98.2\%), KCl (Saarchem, 98.5\%), $\mathrm{Na}_{2} \mathrm{HPO}_{4}$ (Nice laboratory chemicals, 99\%), isobutyraldehyde (Aldrich, 98\%), formaldehyde solution (Merck, min 37\%), dimethylamine solution (Riedel-de Haën, ca. 40\%), $\mathrm{NaBH}_{4}$ (Aldrich, 99\%), $\mathrm{N}$-methyl-2-pyrrolidinone (SigmaAldrich, $\geq 99 \%)$, 1-bromododecane (Aldrich, 97\%), styrene monomer (Merck, $\geq 99 \%)$, maleic anhydride (Merck, 99\%), 2,2'-azobis(2-methylpropionitrile) (AIBN) (SigmaAldrich, $98 \%$, recrystallized from methanol), ethyl methyl ketone (MEK) (Merck, $\geq 99.5 \%$ ), heptane (Sigma-Aldrich, 99\%), (3-aminopropyl)triethoxysilane (3-APTES) (Aldrich, 99\%), THF (Sigma-Aldrich, 99.5\%), isopropanol (SigmaAldrich, $\geq 99 \%$ ), DMF (Associated chemical enterprises, 99\%), 3-(N,N-dimethylamino)-1-propylamine (Aldrich, 99\%), diethyl ether (Sigma-Aldrich, 99.5\%), pentane (Sigma-Aldrich, 99.5\%), hexane (Sigma-Aldrich, 99.5\%).

\subsection{Synthesis of iron oxide nanoparticles immobilized with Con $A$ and quaternized chitosan coated nanoparticles}

Chitosan coated iron oxide nanoparticles were synthesized followed by modification via crosslinking (with glutaraldehyde) and activation with linker molecules (glycine and 1-ethyl-3-(3-dimethylaminopropyl) carbodiimide (EDC)) as illustrated in Fig. 1b. Con A was immobilized onto the dried CS-EDC nanoparticles. Quaternized chitosan $\left(C S-\mathrm{qC}_{12}\right)$ was synthesized and used to coat the SPMNs [18].

\subsubsection{Chitosan coated SPMNs}

The experiment was performed under $\mathrm{N}_{2}$ atmosphere. $100 \mathrm{~mL}$ of $0.5 \%(\mathrm{v} / \mathrm{v})$ aqueous acetic acid was bubbled in a round bottom flask for $30 \mathrm{~min}$. Different weights of $0.08 / 0.4 / 0.73 \mathrm{~g}$ solid chitosan $(0.1 / 0.5 / 0.9 \mathrm{~g}$ chitosan per $1 \mathrm{~g} \mathrm{Fe}_{3} \mathrm{O}_{4}$ ) was dissolved in acetic acid for $2 \mathrm{~h}$ at $80^{\circ} \mathrm{C}$.

$\mathrm{FeCl}_{3} \cdot 6 \mathrm{H}_{2} \mathrm{O}(1 \mathrm{~g})$ and $\mathrm{FeCl}_{2}(0.235 \mathrm{~g})$ was added and dissolved for $30 \mathrm{~min}$. A pale brown solution was obtained. Degassed ammonium hydroxide $(25 \%, 17.4 \mathrm{~mL})$ was rapidly added with vigorous stirring to precipitate the chitosan coated nanoparticles. The solution turned black and was stirred for $1 \mathrm{~h}$. The solution was sonicated in a round bottom flask at $70^{\circ} \mathrm{C}$ for $45 \mathrm{~min}$. The black precipitate was isolated with a magnet and washed 4 times with ethanol and degassed water. The sample was placed in a vacuum oven at $60^{\circ} \mathrm{C}$ for $24 \mathrm{~h}$. The nanoparticle aggregates were milled to a fine powder.

\subsubsection{Chitosan modified with linker molecules Chitosan} coated nanoparticles $(1 \mathrm{~g})$ were dispersed in $125 \mathrm{~mL}$ distilled water and $25 \mathrm{~mL}$ glutaraldehyde $(50 \%, 5.6 \mathrm{M})$.
The solution was stirred at $400 \mathrm{rpm}$ for $8 \mathrm{~h}$. The obtained nanoparticles were washed 3 times with ethanol and water. The nanoparticles where placed in a vacuum oven at $60^{\circ} \mathrm{C}$ for $24 \mathrm{~h}$. The crosslinked chitosan coated nanoparticles $(1 \mathrm{~g})$ were suspended in $100 \mathrm{~mL}$ distilled water, $100 \mathrm{~mL}$ ethanol and $10 \mathrm{~g}$ epichlorohydrin. The mixture was refluxed at $100{ }^{\circ} \mathrm{C}$ for $3 \mathrm{~h}$. The product was magnetically separated and washed with ethanol and distilled water. Glycine $(10 \mathrm{~g})$ was suspended in $200 \mathrm{~mL}$ of 1,4-dioxane in a round bottom flask. This solution was mixed with the produced nanoparticles and $80 \mathrm{~mL}$ of $1.0 \mathrm{M} \mathrm{NaOH}$ was added. The mixture was refluxed for $12 \mathrm{~h}$ at $100{ }^{\circ} \mathrm{C}$ followed by magnetic separation. The product was washed with water and acetone and placed in a vacuum oven to dry. The produced nanoparticles (CS-GLU-GLY, $1 \mathrm{~g}$ ) were dispersed in $40 \mathrm{~mL}$ phosphate buffered saline (PBS) solution. EDC $(0.1 \mathrm{~g})$ was added and the mixture stirred at $400 \mathrm{rpm}$ for $8 \mathrm{~h}$. The nanoparticles were collected with a magnet and washed 5 times with PBS. The nanoparticles were placed in a vacuum oven to dry.

2.2.1.2 Con A immobilization The nanoparticles $(50 \mathrm{mg}$ ) were placed in $1 \mathrm{~mL}$ of a PBS solution containing Con A (4 mg/mL), $\mathrm{MgCl}_{2}(0.01 \mathrm{mg} / \mathrm{mL})$ and $\mathrm{CaCl}_{2}(0.01 \mathrm{mg} /$ $\mathrm{mL}$ ). The samples were incubated in a laboratory shaker at $37^{\circ} \mathrm{C}$ for $1 \mathrm{~h}$, followed by rinsing with PBS ( 3 times for $10 \mathrm{~min}$ at a time) and dried under ambient conditions in a vacuum oven.

\subsubsection{Modification agent for $\mathrm{CS}-\mathrm{qC} \mathrm{C}_{12}$ (3-dimethylamino-2,2-dimethylpropanal)}

Isobutyraldehyde $(50.40 \mathrm{~g}, 0.7 \mathrm{~mol})$ and aqueous $37 \%$ formaldehyde solution $(56.7 \mathrm{~g}, 0.7 \mathrm{~mol}$ ) was placed in a three neck round bottom flask to which $40 \%$ dimethylamine solution $(78.75 \mathrm{~g}, 0.7 \mathrm{~mol})$ was added. The reaction $\left(\mathrm{pH} \mathrm{11)}\right.$ was heated to $100{ }^{\circ} \mathrm{C}$ and purged with $\mathrm{N}_{2}$ gas for $5 \mathrm{~h}$. Thereafter the nitrogen gas was removed and the reaction refluxed for a further $24 \mathrm{~h}$. The reaction was cooled and separated using a separating funnel. The organic phase (bottom layer) was placed in a rotary evaporator to remove the aqueous phase. An orange liquid product was obtained.

The produced modification agent (3-dimethylamino2,2-dimethylpropanal) can selectively form a Schiff base with the amino groups of chitosan. A reducing agent, $\mathrm{NaBH}_{4}$, can then be added resulting in $\mathrm{N}$-substituted chitosan. $\mathrm{N}$-substituted chitosan can react with an alkyl bromine, where the tertiary amine groups of chitosan can attack the electropositive carbon atoms attached to the bromine via nucleophilic substitution. 
2.2.2.1 CS-qC $12 \quad$ (N,N-(2-dimethyl)propyl-3-N', N'-dimethyl-N'-dodecylammonium chitosan chloride) Chitosan $(3 \mathrm{~g})$ was dissolved in $300 \mathrm{~mL}$ of $0.5 \%$ acetic acid at room temperature after which 3-dimethylamino-2,2-dimethylpropanal $(6.46 \mathrm{~g}, 0.05 \mathrm{~mol})$ was added while stirring. After $24 \mathrm{~h}, 10 \% \mathrm{NaBH}_{4}(0.15 \mathrm{~mol})$ was added and the reaction was stirred for $24 \mathrm{~h}$. The white product was precipitated in acetone, filtered and dried at $60^{\circ} \mathrm{C}$ for $24 \mathrm{~h}$. $\mathrm{N}$-substituted chitosan ( $3 \mathrm{~g})$ was dispersed in $\mathrm{N}$-methyl-2-pyrrolidone $(150 \mathrm{~mL})$ and $1.5 \mathrm{~mL}$ acetic acid for $24 \mathrm{~h}$. At this point 1-bromododecane $(27 \mathrm{~g})$ was added dropwise, the reaction heated to $100^{\circ} \mathrm{C}$ and stirred for $48 \mathrm{~h}$. The yellow product was precipitated in excess acetone, filtered and dried at $60^{\circ} \mathrm{C}$ for $24 \mathrm{~h}$.

The pristine iron oxide nanoparticles were activated with 3-APTES followed by coating with SMA (synthesis detailed in Online Resource 1) and further functionalization to form SMI-qC $\mathrm{C}_{12}$ (illustrated in Fig. 1c) coated SPMNs. The SMA coated SPMNs were also immobilized with Con A, similar to Con A immobilized chitosan (CS-EDC-Con A).

\subsection{Synthesis of SMA coated SPMNs}

Milled $\mathrm{Fe}_{3} \mathrm{O}_{4}$ nanoparticles $(1 \mathrm{~g})$ were soaked in $60 \mathrm{~mL}$ methanol in a three-necked round bottom flask and sonicated for $30 \mathrm{~min}$. Ammonium hydroxide $(6 \mathrm{~mL}, 25 \%$ in water) was added and sonicated further for $10 \mathrm{~min}$. 3-APTES $(4 \mathrm{~mL})$ was added dropwise under $\mathrm{N}_{2}$ atmosphere and vigorous stirring and heated to $50^{\circ} \mathrm{C}$ for $8 \mathrm{~h}$. The 3-APTES activated nanoparticles were magnetically separated, washed with ethanol and water and then dried in a vacuum oven. SMA $(0.1 \mathrm{~g} / 0.5 \mathrm{~g} / 0.9 \mathrm{~g})$ was dissolved in $100 \mathrm{~mL} \mathrm{THF}$ in a round bottom flask. 3-APTES SPMNs $(1 \mathrm{~g})$ were added while stirring, followed by sonication for $15 \mathrm{~min}$. The reaction was then refluxed for $3 \mathrm{~h}$ at $60^{\circ} \mathrm{C}$. The reaction was cooled, isopropanol added to precipitate the SMA and the SMA coated SPMNs magnetically separated. The coated nanoparticles were washed with hexane and dried in a vacuum oven at $60^{\circ} \mathrm{C}$ [18].

\subsection{1 $\mathrm{SMI}-\mathrm{qC}_{12}$ coated SPMNs}

SMA (1 g) coated SPMNs were dispersed in $25 \mathrm{~mL}$ of DMF followed by adding 3-( $\mathrm{N}, \mathrm{N}$-dimethylamino)-1-propylamine $(3.3 \mathrm{~g})$ dropwise to the solution. The reaction was heated and refluxed at $170^{\circ} \mathrm{C}$ for $2 \mathrm{~h}$. The reaction was cooled, precipitated in diethyl ether and magnetically separated. The SMI-tC coated SPMNs were dried in a vacuum oven at $60^{\circ} \mathrm{C}$. SMI-tC $(1 \mathrm{~g})$ coated SPMNs were dispersed in $20 \mathrm{~mL}$ of DMF at room temperature. 1-bromododecane (1.15 g) was added dropwise while stirring and the reaction was heated to $110^{\circ} \mathrm{C}$ for $48 \mathrm{~h}$. The reaction mixture was then cooled, precipitated in diethyl ether, magnetically separated and washed 3 times with pentane. The $\mathrm{SMI}-\mathrm{qC} \mathrm{C}_{12}$ SPMNs were dried in a vacuum oven at $60^{\circ} \mathrm{C}$ [18].

\subsection{BCG-mCherry affinity studies}

mCherry-expressing BCG (BCG-mCherry) was obtained by transforming BCG Pasteur with pMSG432 (episomal plasmid encoding $m C h e r r y$ and enabling hygromycin resistance). The BCG-mCherry strains were grown at $37^{\circ} \mathrm{C}$ in Middlebrook $7 \mathrm{H} 9$ growth medium supplemented with $10 \%$ albumin /dextrose/saline, $0.5 \%$ glycerol and $0.05 \%$ Tween80 in $50 \mu \mathrm{g} / \mathrm{mL}$ hygromycin to an $\mathrm{OD}_{600 \mathrm{~nm}}$ of 1 . The culture was subsequently inoculated in $20 \mathrm{ml}$ Sauton's medium $\left(\mathrm{OD}_{600 \mathrm{~nm}}=0.05\right)$ and further incubated at $37^{\circ} \mathrm{C}$ until the culture reached an $\mathrm{OD}_{600 \mathrm{~nm}}$ of 7. During the affinity studies $50 \mathrm{mg}$ nanoparticles were placed in polytops followed by pipetting in a $5 \mathrm{~mL}$ aliquot of BCG culture solution and sealing the polytops with parafilm. The polytops were incubated at $37^{\circ} \mathrm{C}$ for $1 \mathrm{~h}(\mathrm{pH}$ 7) on a laboratory shaker. The nanoparticles were separated with a magnet and washed three times in PBS for 10 min followed by placing the nanoparticles in clean polytops [18].

\subsection{Characterization}

\subsubsection{Powder X-ray diffraction (P-XRD)}

A Siemens D8 Advance diffractometer using Cu Ka radiation $(\lambda=1.5406 \AA)$ operated at $40 \mathrm{kN}$ and $30 \mathrm{~mA}$ was utilized to determine the structural properties of the pristine SPMNs. XRD patterns were recorded in the range $10-80^{\circ}$

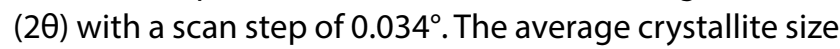
$(<D\rangle, \AA)$ could be calculated from line broadening of the XRD spectrum using the Scherrer formula.

$D_{p}=\frac{\mathrm{k} \lambda}{\beta \cos \theta}$

where $D_{p}$ is the average size of the crystalline domains, $k$ is the Scherrer constant (0.89), $\lambda$ is the $X$-ray wavelength $(1.5406 \mathrm{~nm}), \beta$ is the peak full width at half maximum (FWHM) and $\theta$ is the Bragg diffraction angle.

The samples were dried for $24 \mathrm{~h}$ in a vacuum oven at room temperature before analysis, followed by milling the nanoparticles into a fine powder and uniformly packing the nanoparticles into a sample holder to insure a quality diffractogram. The obtained spectrum was corrected for instrumental line broadening and baseline corrected.

\subsubsection{Transmission electron microscopy (TEM)}

TEM was utilized to determine the particle size and morphology of the nanoparticles. A JEM 1200EXII model (JEOL, 
Japan) microscope was used with an accelerated voltage of $120 \mathrm{kV}$ for all the samples. The samples were dried in a vacuum oven at $60^{\circ} \mathrm{C}$ for $24 \mathrm{~h}$ followed by milling into a powder. $1 \mathrm{mg}$ of the polymer coated SPMN samples was dispersed in distilled water and sonicated for $10 \mathrm{~min}$, after which a drop was pipetted on a carbon-coated 200 mesh copper grid. The BCG-mCherry captured SPMNs were dispersed in PBS. The samples were dried under ambient conditions, attached to the sample holder and placed in the microscope. An average diameter and size-distribution could be determined by measuring more than 100 particles.

\subsubsection{Thermogravimetric analysis (TGA)}

TGA was performed with a Q500 TA instrument in the temperature range of $25-600{ }^{\circ} \mathrm{C}$. Pt crucibles were used with about $6 \mathrm{mg}$ dried nanoparticles, under dynamic $\mathrm{N}_{2}$ atmosphere $(50 \mathrm{~mL} / \mathrm{min})$ and a heating rate of $10{ }^{\circ} \mathrm{C} / \mathrm{min}$. The sample holder was calibrated and the samples weighed in a sample component that was flushed with $\mathrm{N}_{2}$ gas and dried.

\subsubsection{Attenuated total reflectance Fourier transform infrared spectroscopy (ATR-FTIR)}

Infrared spectra were obtained using a Nicolet FTIR spectrometer from Thermo-Fischer. An ATR accessory with a diamond/ZnSe internal reflection crystal was attached. The spectra were recorded from 4000 to $500 \mathrm{~cm}^{-1}$ with a spectral resolution of $4 \mathrm{~cm}^{-1}$. 64 individual scans were taken to generate the spectra as well as 32 scans for the background spectra before each sample. Omnic software, version 8.1, was used for data acquisition and processing.

\subsubsection{Horseradish peroxidase (HRP) enzymatic assay}

A HRP assay was used to determine the biological activity of Con A immobilized to the nanoparticles. The enzymatic assay of peroxidase (EC 1.11.1.7) (Sigma Aldrich) with ABTS as a substrate was used. The assay was adapted, where the absorbance was measured for $30 \mathrm{~min}$ and the fastest rate used to determine the units/mg solid. $50 \mathrm{mg}$ CS-EDC-Con A nanoparticles were incubated in $1.0 \mathrm{~mL}$ dilute enzyme solution ( $1 \mathrm{mg} / \mathrm{L}$ ) for $3 \mathrm{~h}$ on a laboratory shaker at $\mathrm{rt}$, followed by washing with diluent.

$\frac{\text { units }}{m g}=\frac{\frac{\Delta \mathrm{A}_{405 \mathrm{~nm}}}{\mathrm{~min}}(\text { sample })-\frac{\Delta \mathrm{A}_{405 \mathrm{~nm}}}{\min }(\text { blank }) \times 3.05 \times \mathrm{DF}}{36.8 \times 0.05}$

$3.05=$ Final volume in cuvette (millilitres).

$\mathrm{DF}=$ Dilution factor of enzyme.
36.8 = Millimolar extinction coefficient of oxidised ABTS at $\mathrm{A}_{405 \mathrm{~nm}}$.

$0.05=$ Volume enzyme used (millilitres).

\subsubsection{Superconducting quantum interference device (SQUID)}

A SQUID magnetometer was utilized to determine the magnetic nature of pristine SPMNs and polymer coated nanoparticles. A reciprocal sample option was chosen for the samples and performed on a SQUID magnetometer (7 T Magnet). A 10-7 electromagnetic units (emu) resolution was reached. A liquid SPMN sample $(50 \mathrm{mg}$ of $50 \mathrm{mmol} / \mathrm{L}$ ) was embedded in specific drop-shaped cuvettes ( $5 \mathrm{~mm}$ diameter and $15 \mathrm{~mm}$ length). Hysteresis curves were determined at $300 \mathrm{~K}$ fixed temperature with a field strength of 0 to $30 \mathrm{kOe}$. The background of the diamagnetic part of the cuvette was minimized by performing all measurements in a parallel magnetic field in the longitudinal direction to the cuvette. The specific magnetization was calculated in emu/g iron using the signal intensity of the magnetization (emu) and the exact net weight.

\subsubsection{Fluorescence microscopy (FM)}

The modified chitosan and SMA coated SPMNs were imaged using a Zeiss LSM 880 confocal microscope (ZEN 2.3 software) coupled with an Argon multiline laser. The nanoparticles were sonicated in PBS for $10 \mathrm{~s}$ followed by placing a drop on the microscope slide. An argon laser with an excitation wavelength of $543 \mathrm{~nm}$ was used (GaAsP detector $32+2$ PMT) for excitation of mCherry fluorescence. Transmission and Light microscopy images were obtained simultaneously with a transmitted light detector T-PMT.

\section{Results and discussion}

\subsection{XRD}

Pristine $\mathrm{Fe}_{3} \mathrm{O}_{4}$ nanoparticles were synthesized and powder $X$-ray diffraction (P-XRD) was used to determine the crystallinity and the phase purity of the nanoparticles as seen in Fig. 2a. The XRD diffractogram obtained was compared to literature as well as the database standard for magnetite (JCPDS file No.00-019-0629). It was found that the XRD pattern and relative intensities correlated to literature with characteristic peaks at $2 \theta=18.4,30.2,35.6,43.2,53.6,57.2$, 62.8 and $74.2^{\circ}$ corresponding to the (111), (220), (311), (400), (422), (511), (440) and (533) planes respectively $[11,19]$. The average crystallite size of the pristine $\mathrm{Fe}_{3} \mathrm{O}_{4}$ 
(b)

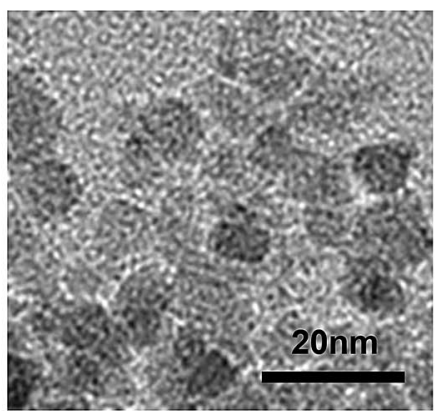

(d)

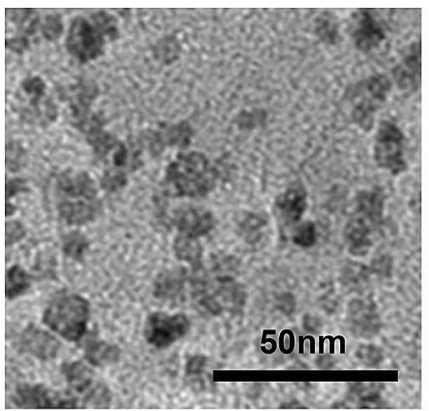

(c)

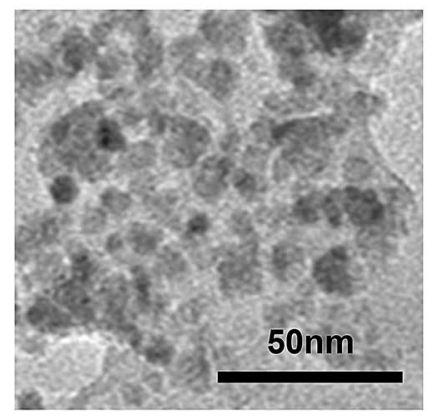

(e)

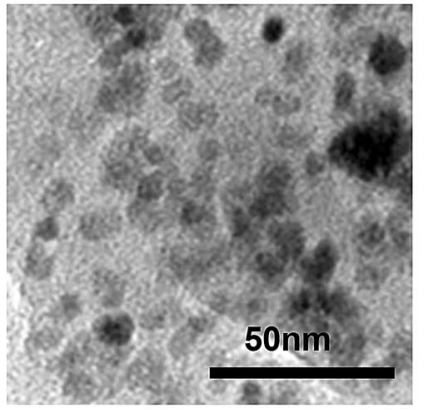

Fig. 2 a XRD diffractogram of $\mathrm{Fe}_{3} \mathrm{O}_{4}$ SPMNs, TEM images of b pristine SPMNs, c $0.1 \mathrm{~g}$ CS-EDC-Con A SPMNs, d $0.5 \mathrm{~g}$ CS-EDC-Con A SPMNs and e $0.9 \mathrm{~g}$ CS-EDC-Con A SPMNs

nanoparticles, using the Scherrer equation, was calculated to be $6.6 \mathrm{~nm}$.

\subsection{TEM}

The SMI-qC $\mathrm{C}_{12}$ coated SPMNs had the highest overall affinity for BCG-mCherry and were thus characterized. CS-EDCCon A coated SPMNs had the highest affinity w.r.t the chitosan coated nanoparticles and were thus also analyzed. TEM was used to determine the effect of polymer loading on the iron oxide nanoparticles with respect to morphology, diameter and size distribution. The pristine uncoated nanoparticles were aggregated, Fig. 2b, compared to the polymer coated nanoparticles with 0.1 and $0.5 \mathrm{~g}$ polymer coating (c and d). Aggregation is observed for uncoated nanoparticles due to the nanoparticles that have attraction towards each other. Coating with a polymer shell enhanced the dispersion in aqueous solution [15]. The nanoparticles with $0.9 \mathrm{~g}$ polymer loading (e), however, showed aggregation, possibly due to the polymer coating of adjacent nanoparticles binding to each other. The uncoated and coated nanoparticles were largely spherical and had a slight increase in diameter with the increase in polymer loading. The average diameter of the pristine iron oxide nanoparticles were $8.2 \pm 2.1 \mathrm{~nm}$, followed by $8.7 \pm 2.0 \mathrm{~nm}, 10.2 \pm 2.9 \mathrm{~nm}$ and $12.5 \pm 6.2 \mathrm{~nm}$ for the $0.1 \mathrm{~g}$, $0.5 \mathrm{~g}$ and $0.9 \mathrm{~g}$ CS-EDC-Con A SPMNs respectively. Whereas the $\mathrm{SMI}-\mathrm{qC} \mathrm{C}_{12}$ coated nanoparticles had average diameters of $9.3 \pm 2.6 \mathrm{~nm}, 10.1 \pm 1.8 \mathrm{~nm}$ and $10.2 \pm 2.1 \mathrm{~nm}$ for the 0.1 , $0.5 \mathrm{~g}$ and $0.9 \mathrm{~g}$ polymer loadings, respectively. A thin layer of modified chitosan and SMI-qC $\mathrm{C}_{12}$ coated the nanoparticles and thus lead to an increase in diameter.

\subsection{TGA}

The percentage content of the polymeric coating around the SPMN core was determined via TGA. The TGA curves of the modified chitosan (CS-EDC) and modified SMA (SMI$\mathrm{qC}_{12}$ ) with $0.1,0.5$ and $0.9 \mathrm{~g}$ polymer loading are depicted in Fig. 3a-f. The weight loss steps were compared to literature which enabled characterization. Three distinct weight loss steps are observed for the polymer coated SPMNs. The first weight loss step is due to the loss of adsorbed water on the polymer surface as well as surface hydroxyls. This weight loss step occurred form $25-100^{\circ} \mathrm{C}$ for the SMI-qC ${ }_{12}$ SPMNs (2-3\% weight loss) and from 25 to $150^{\circ} \mathrm{C}$ for the CS-EDC SPMNs (4-8\% weight loss). CS-EDC is more hydrophilic compared to $\mathrm{SMI}_{\mathrm{qC}} \mathrm{C}_{12}$ and will thus adsorb more water to the polymer surface. The second and third weight loss steps occurred from 100 to $600^{\circ} \mathrm{C}$ for the SMI$\mathrm{qC}_{12}$ SPMNs and from 150 to $600^{\circ} \mathrm{C}$ for the CS-EDC SPMNs. These weight loss steps can be attributed to the released volatiles and disintegration of the polymer coating [16, 20]. Pristine SPMNs had a minor weight loss of $2 \%$ from 


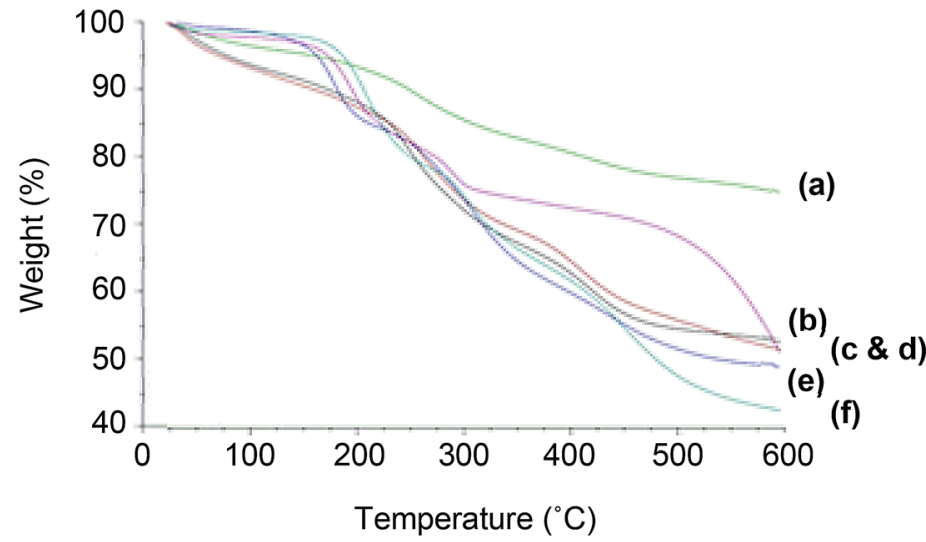

(j)

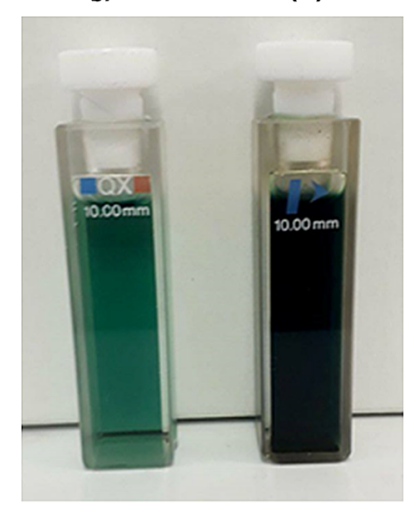

Fig. 3 TGA curves and coating \% of a $0.1 \mathrm{~g}$ CS-EDC SPMNs (17.8 wt\%), b $0.9 \mathrm{~g}$ CS-EDC SPMNs (34.0 wt\%), c $0.5 \mathrm{~g}$ CS-EDC SPMNs (34.3 wt\%), d $0.5 \mathrm{~g} \mathrm{SMI-qC}{ }_{12}$ SPMNs (45.0 wt\%), e $0.1 \mathrm{~g} \mathrm{SMI-qC}$ SPMNs (44.0 wt\%), f $0.9 \mathrm{~g} \mathrm{SMI}^{-q C_{12}}$ SPMNs (52.5 wt\%), FTIR of $\mathbf{g}$

100 to $600^{\circ} \mathrm{C}$. The coated polymers had a weight loss due to degradation of the polymer coating in this temperature range and Eq. 3 can thus be used to determine the percentage polymer coating.

Coating $\%=\mathrm{W}_{\mathrm{c}}(\%)-\mathrm{W}_{\mathrm{u}}(\%)$

where $\mathrm{W}_{\mathrm{c}}(\%)$ is the percentage of polymer weight lost by the modified chitosan and SMA coated iron oxide nanoparticles and $\mathrm{W}_{\mathrm{u}}(\%)$ is the percentage weight lost by the uncoated iron oxide nanoparticles. The $\mathrm{SMI}_{\mathrm{q}} \mathrm{qC} \mathrm{C}_{12}$ SPMNs had a higher weight percentage polymer coating compared to the CS-EDC SPMNs. This could be due to the nanoparticle synthesis, in situ chitosan coating followed by modification vs. SMA coating of pristine iron oxide nanoparticles and modification. Other factors such as the hydrophobicity and crystallinity of SMA, size of the polymer and packing density also affect the coating
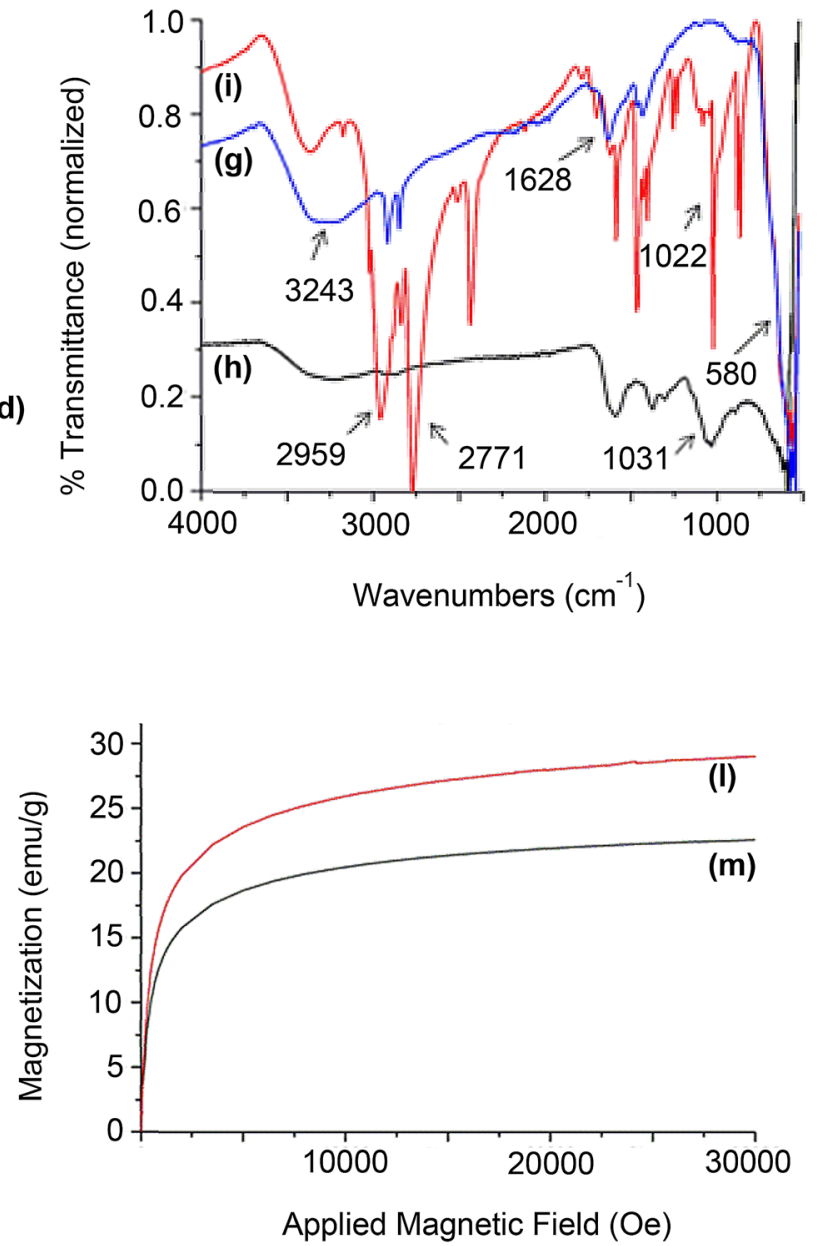

uncoated SPMNs, $\mathbf{h}$ CS-EDC SPMNs and i SMI-qC ${ }_{12}$ SPMNs, CS-EDCCon A SPMNs $\mathbf{j}$ without HRP and $\mathbf{k}$ with HRP, SQUID magnetization curves of I pristine (uncoated) SPMNs and $\mathbf{m}$ chitosan coated SPMNs

percentage. A higher coating percentage was achieved with $0.9 \mathrm{~g}$ polymer loading compared to $0.1 \mathrm{~g}$ polymer loading.

\subsection{ATR-FTIR}

ATR-FTIR spectra were utilized to confirm the polymer coating of CS-EDC and $\mathrm{SMI}_{-\mathrm{qC}}$, around the superparamagnetic magnetite nanoparticles. The FTIR spectra is illustrated in Fig. 3 CS-EDC SPMNs (h), SMI-qC 12 SPMNs (i) and pristine (uncoated) SPMNs (g). The FTIR spectra illustrate that CS-EDC and $\mathrm{SMI}_{-\mathrm{qC}}$ 12 was functionalized onto the iron oxide core. The characteristic $\mathrm{Fe}-\mathrm{O}$ vibration of magnetite is observed at $580 \mathrm{~cm}^{-1}$ for pristine iron oxide nanoparticles as well as the polymer coated nanoparticles. An O-H stretch $\left(3243 \mathrm{~cm}^{-1}\right)$ and bend vibration $\left(1628 \mathrm{~cm}^{-1}\right)$ can also be assigned for the uncoated nanoparticles due to surface hydroxyl groups. The CS-EDC 
SPMNs had a C-O vibration at $1031 \mathrm{~cm}^{-1}$ which is characteristic of the chitosan polymer backbone [21]. For the $\mathrm{SMI}_{\mathrm{q}} \mathrm{q} \mathrm{C}_{12}$ SPMNs a significant increase in the intensity of the bands at 2959 and $2771 \mathrm{~cm}^{-1}$ can be attributed to the methyl and methylene stretch vibrations of the $\mathrm{SMI}-\mathrm{qC}_{12}$ alkyl chains. An additional vibration at $1022 \mathrm{~cm}^{-1}$ can be assigned to the $\mathrm{Si}-\mathrm{O}$ symmetric stretch of 3-APTES used for nanoparticle surface activation [22].

\subsection{HRP enzymatic assay}

An HRP enzymatic assay was performed on the CS-EDCCon A nanoparticles to determine the biological activity of the immobilized Con A (Fig. 3j, k). A colour change from green (j) to dark blue (k) was observed for the CSEDC-Con A-HRP nanoparticles which confirm qualitatively that HRP was bound to biologically active Con A immobilized to the nanoparticles. The amount of biologically active Con A immobilized to the nanoparticles was quantitatively determined to be $7.5 \%$. The $\%$ biologically active Con $A$ is comparable to literature [23].

\subsection{SQUID}

SQUID was used to determine the magnetic properties (saturation magnetization and superparamagnetic behaviour) of the synthesized magnetite nanoparticles. For superparamagnetic nanoparticles the size of the nanoparticles are smaller than the critical limit (14 nm) in which single domain nanoparticles are observed. When an external magnetic field is applied the single domain magnets will align all their magnetic moments in the same direction. The resulting magnetization is thus the largest possible for that specific material and size. Superparamagnetic particles are characterized by zero magnetic remanence and coercivity in the absence of an external magnetic field and will thus not have magnetic memory [24]. The magnetization curves of pristine SPMNs (I) and chitosan coated SPMNs $(\mathrm{m})$ are shown in Fig. 3. The curve represents the long moment or magnetization as a function of the applied magnetic field (at $300 \mathrm{~K}$ ). The SQUID results indicated that the uncoated and chitosan coated nanoparticles were superparamagnetic due to zero coercivity and zero remanence. The saturation magnetization was $29.0 \mathrm{emu} / \mathrm{g}$ for the uncoated nanoparticles compared to $22.6 \mathrm{emu} / \mathrm{g}$ for the chitosan coated nanoparticles. The polymeric coating thus decreased the effective magnetic moment but superparamagnetic properties were retained [22].

\subsection{BCG-mCherry affinity studies}

\subsubsection{Fluorescence microscopy}

The nanoparticles with different polymer loadings $(0.1,0.5$ and $0.9 \mathrm{~g}$ ) were evaluated and compared for BCG-mCherry capture (Fig. 4a, b) and Online Resource 2) where FM is used to visualize the nanoparticles attached to the bacteria. Sample preparation did not enable quantitative analysis. The samples had to be sonicated for dispersion of the nanoparticles, this however lead to unattached bacteria on the FM images. The unattached bacteria influenced the fluorescence intensity. It was also noted that not all the attached bacteria had the same fluorescence intensity. A qualitative approach at each dilution was thus used to determine the extent of bacterial attachment. A dilution study with ten-fold serial dilutions was performed to determine the limit of detection. LM overlaid with FM was used to visualize the morphology at the given area (Online Resource 3). The pristine SPMNs did not have fluorescence at the excitation wavelength of BCGmCherry. The SMI-qC $\mathrm{C}_{12}$ and CS-EDC-Con A coated SPMNs had similar BCG-mCherry affinity for the initial dilution of $\mathrm{OD}_{600 \mathrm{~nm}}=7 / 21.91 \times 10^{7} \mathrm{CFU} / \mathrm{mL}$ as seen in Table 1. Only the $0.9 \mathrm{~g}$ CS-EDC-Con A SPMNs had less rod-shaped captured bacteria but fluorescence was still observed.

After the second dilution of $\mathrm{OD}_{600 \mathrm{~nm}}=0.7 / 2.19 \times 10^{7} \mathrm{CFU} / \mathrm{mL}$ however no fluorescence were observed for the $0.5 \mathrm{~g}$ CS-EDC-Con A SPMNs and $0.9 \mathrm{~g}$ CS-EDC-Con A SPMNs. Fluorescence was observed from captured bacteria for the $0.1 \mathrm{~g}$ CS-EDC-Con A SPMNs, thus corresponding to the limit of detection of CS-EDC-Con A. After the third dilution of $\mathrm{OD}_{600 \mathrm{~nm}}=0.07 / 0.22 \times 10^{7} \mathrm{CFU} /$ $\mathrm{mL}$ only the $\mathrm{SMI}_{\mathrm{q}} \mathrm{qC}_{12}$ SPMNs captured bacteria, this concentration is the limit of detection for the $\mathrm{SMI}_{\mathrm{q}} \mathrm{qC} \mathrm{C}_{12}$ SPMNs. The SMI-qC $\mathrm{C}_{12}$ SPMNs thus had the highest affinity for BCG-mCherry. The effect of the polymer loading could not be estimated from FM as the $0.1,0.5$ and $0.9 \mathrm{~g}$ SMI-qC $C_{12}$ SPMNs had similar BCG-mCherry affinity at the lowest $\mathrm{OD}_{600 \mathrm{~nm}}=0.07$ dilution. The adhesion of the nanoparticles to the bacteria was thus investigated with TEM. The positively charged quaternary ammonium moieties of $\mathrm{SMI}-\mathrm{qC} \mathrm{C}_{12}$ can interact with the negatively charged electron dense bacteria cell wall (lipid layer) via electrostatic interaction. The electrostatic interaction leads to attachment of the bacteria to the nanoparticle surface. The hydrophobic alkyl chains of $\mathrm{C}_{12}$ can also attach to the hydrophobic outer layer (mycolic acids) of the bacteria cell wall which contributes to BCG-mCherry affinity [25]. Con A can bind to the carbohydrate based structures on the surface of BCG$m C h e r r y ~ s u c h$ as mannose. Mannose is present in the form of mannose-capped lipoarabinomannan (Man-LAM) and is accessible for specific interactions with Con A [26]. 
Fig. 4 FM images at $\mathrm{OD}_{600 \mathrm{~nm}}=7$ for $0.5 \mathrm{~g}$ CS-EDCCon A SPMNs a FM and $\mathbf{b}$ LM overlaid with FM, TEM images of nanoparticles incubated with BCG-mCherry at $\mathrm{OD}_{600 \mathrm{~nm}}=7$ c BCG-mCherry bacteria, d $0.1 \mathrm{~g}$ CS-EDC-Con A SPMNs, e $0.5 \mathrm{~g}$ CS-EDC-Con A SPMNs, f $0.5 \mathrm{SMI}^{-q C_{12}}$ SPMNs and $\mathbf{g} 0.9 \mathrm{SMI}^{-\mathrm{qC}_{12}}$ SPMNs

(a)

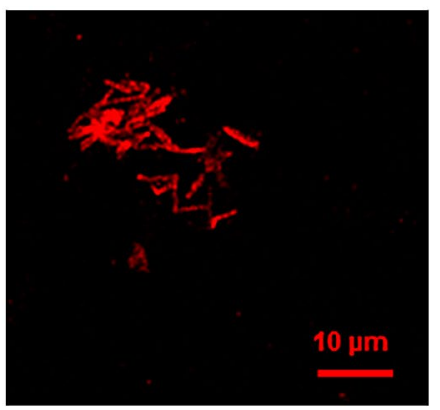

(d)

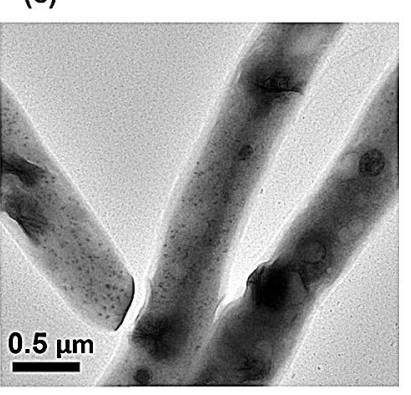

(f)

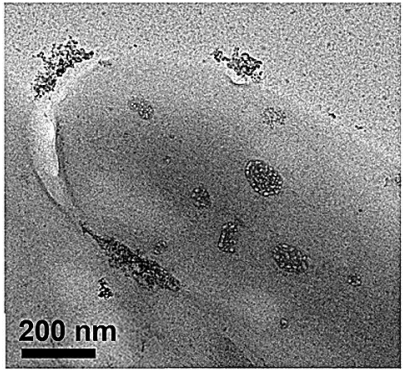

(b)

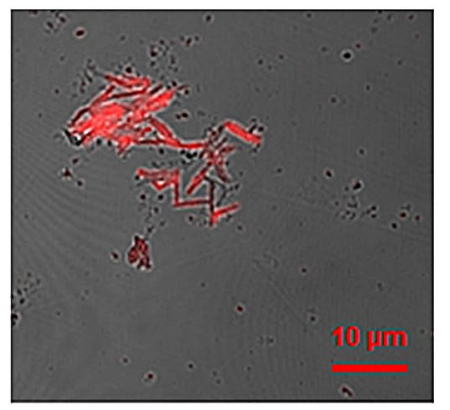

(e)

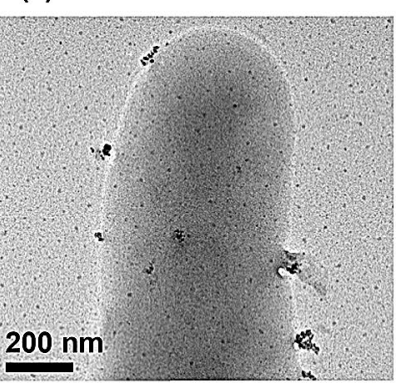

(g)
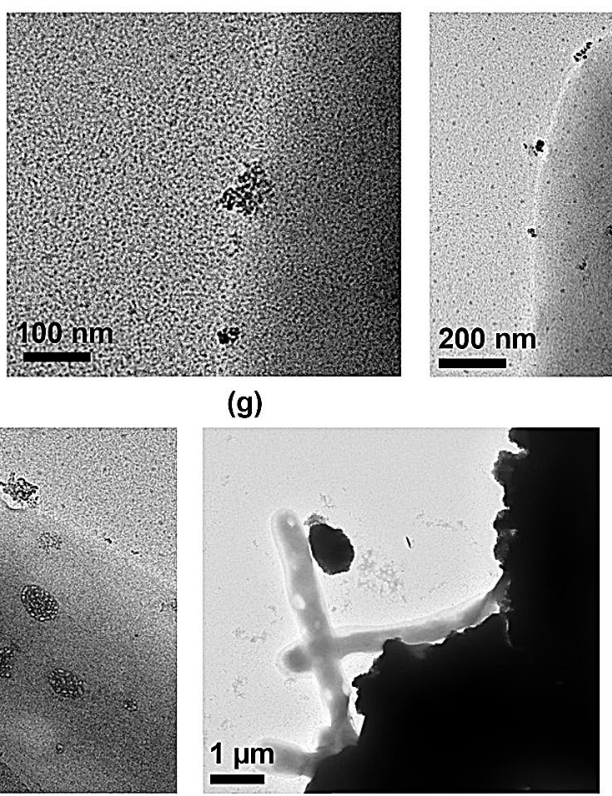

Table 1 Qualitative FM and TEM summary of BCG-mCherry captured by SPMNs

\begin{tabular}{|c|c|c|c|c|c|c|}
\hline & $\begin{array}{l}0.1 \mathrm{~g} \text { CS-EDC- } \\
\text { Con A SPMNs }\end{array}$ & $\begin{array}{l}0.5 \mathrm{~g} \text { CS-EDC- } \\
\text { Con A SPMNs }\end{array}$ & $\begin{array}{l}0.9 \mathrm{~g} \text { CS-EDC- } \\
\text { Con A SPMNs }\end{array}$ & $\begin{array}{l}0.1 \mathrm{~g} \\
\text { SMI-qC }_{12} \\
\text { SPMNs }\end{array}$ & $\begin{array}{l}0.5 \mathrm{~g} \\
\text { SMI-qC }_{12} \\
\text { SPMNs }\end{array}$ & $\begin{array}{l}0.9 \mathrm{~g} \\
\text { SMl-qC }_{12} \\
\text { SPMNs }\end{array}$ \\
\hline $\mathrm{OD}_{600 \mathrm{~nm}}=7$ & $x X$ & $X X$ & $x$ & $X X$ & $X X$ & $X X$ \\
\hline $\mathrm{OD}_{600 \mathrm{~nm}}=0.7$ & $x$ & & & $x$ & $x$ & $x$ \\
\hline $\mathrm{OD}_{600 \mathrm{~nm}}=0.07$ & & & & $x$ & $x$ & $x$ \\
\hline TEM OD $_{600 \mathrm{~nm}}=7$ & $x$ & $x$ & & & $x$ & $X X$ \\
\hline
\end{tabular}

${ }^{*} \mathrm{XX}=$ bacterial colonies captured, $\mathrm{X}=$ singe disperse bacteria captured

\subsubsection{TEM}

TEM was used to observe the physical adhesion of the SPMNs to the bacteria. The nanoparticles used at a BCGmCherry dilution of $\mathrm{OD}_{600 \mathrm{~nm}}=7$ were dispersed in PBS, sonicated, placed on TEM grids and dried under ambient conditions. The $0.9 \mathrm{~g}$ CS-EDC-Con A SPMNs and $0.1 \mathrm{~g}$ SMI$\mathrm{qC}_{12}$ SPMNs did not show BCG-mCherry attachment via TEM. In Fig. 4c-g the SPMNs attached to BCG-mCherry can be observed. The large rod shaped bacteria with a diameter of 2.5-4 $\mu \mathrm{m}$ was observed. The polymer coated SPMNs formed darker areas around the bacteria. The interface between the bacteria and the nanoparticles can be seen. A lighter area is observed where the nanoparticles are attached to the bacteria which could be attributed to bacterial shrinkage after drying [27]. The $0.9 \mathrm{~g} \mathrm{SMI-qC}_{12}$ SPMNs showed the highest affinity for BCG-mCherry, Fig. $4 \mathrm{~g}$, where colonies of bacteria were attached to the nanoparticles compared to individual bacteria for the lower polymer loadings. 


\section{Conclusions}

SMI-qC $\mathrm{C}_{12}$, followed by CS-EDC-Con A for the chitosan derivatives, was found to be the polymer-and-functionalmoiety combinations which captured the most BCGmCherry bacteria. The SMI- $\mathrm{qC}_{12}$ coated SPMNs could adhere to the BCG-mCherry cell wall via a combination of hydrophobic and electrostatic interactions. On the other hand, the Con A immobilized to the CS-EDC-Con A SPMNs could adhere to BCG-mCherry via the carbohydrate binding properties of the protein. The SPMNs were thus polymer coated with SMI-qC 12 and CS-EDC-Con A. This coating also prevented aggregation. The nanoparticles were coated with $0.1,0.5$ and $0.9 \mathrm{~g}$ polymer per $1 \mathrm{~g}$ pristine SPMNs to determine the most effective polymer loading. TGA results indicated that a higher coating percentage was achieved for $0.9 \mathrm{~g}$ polymer loading when compared to $0.1 \mathrm{~g}$ polymer loading and a slight increase in the average nanoparticle diameter was seen for the coated SPMNs via TEM. An HRP assay was performed on the CS-EDC-Con A SPMNs, which confirmed the biological activity of Con A immobilized to the nanoparticles. SQUID magnetometry was performed on chitosan coated SPMNs and a decrease in saturation magnetization was observed compared to pristine SPMNs, but the coated SPMNs, however, retained superparamagnetism after polymer coating. The $0.9 \mathrm{~g} \mathrm{SMI-qC_{12 }}$ SPMNs captured the most BCG-mCherry bacteria as determined via $T E M$. The results indicate that non-specific electrostatic and hydrophobic interactions $\left(\mathrm{SMI}^{-\mathrm{qC}} \mathrm{C}_{12}\right.$ ) could lead to a higher BCG-mCherry affinity compared to specific carbohydrate-protein binding (CS-EDC-Con A). There is thus also reason to believe that a higher polymer loading, will lead to a higher coating percentage. A higher coating percentage will result in more available functional groups that can attach to the bacteria. The bacilli in a sample can thus effectively be captured and concentrated by $\mathrm{SMI}-\mathrm{qC}_{12}$ coated SPMNs, followed by extraction via an external magnet. This result, therefore, holds great potential as an aid in the fast and accurate diagnosis of TB using microscopy (FM, scanning electron microscopy (SEM) or TEM).

Acknowledgements The authors thank the National Research Foundation (NRF) and Stellenbosch University for funding.

\section{Compliance with ethical standards}

Conflict of interest On behalf of all authors, the corresponding author states that there is no conflict of interest.

\section{References}

1. Aketi L, Kashongwe Z, Kinsiona C, Fueza SB, Kokolomami J, Bolie G, Lumbala P, Diayisu JS (2016) Childhood tuberculosis in a sub-saharan tertiary facility: epidemiology and factors associated with treatment outcome. PLoS ONE 11:1-14

2. Kaittanis C, Santra S, Perez JM (2010) Emerging nanotechnologybased strategies for the identification of microbial pathogenesis. Adv Drug Deliv Rev 62:408-423

3. Nicol MP, Workman L, Isaacs W, Munro J, Black F, Eley B, Boehme CC, Zemanay W, Zar HJ (2011) Accuracy of the Xpert MTB/ RIF test for the diagnosis of pulmonary tuberculosis in children admitted to hospital in Cape Town, South Africa: a descriptive study. Lancet Infect Dis 11:819-824

4. Liu Y, Lv H, Qin Y, Deng L, Wang Y (2017) Gentamicin modified chitosan film with improved antibacterial property and cell biocompatibility. Int J Biol Macromol 98:550-556

5. Sahariah $P$, Benediktssdóttir BE, Hjálmarsdóttir MA, Sigurjonsson OE, Sørensen KK, Thygesen MB, Jensen KJ, Másson M (2015) Impact of chain length on antibacterial activity and hemocompatibility of quaternary $\mathrm{N}$-alkyl and $\mathrm{N}, \mathrm{N}$-dialkyl chitosan derivatives. Biomacromol 16:1449-1460

6. Li Y, Nie W, Chen P, Zhou Y (2016) Preparation and characterization of sulfonated poly(styrene-alt-maleic anhydride) and its selective removal of cationic dyes. Colloids Surf A Physicochem Eng Asp 499:46-53

7. Cronje L, Warren R, Klumperman B (2013) pH-dependent adhesion of mycobacteria to surface-modified polymer nanofibers. J Mater Chem B 1:6608-6618

8. Cronje L (2012) Surface modification of styrene maleic anhydride nanofibers for efficient capture of Mycobacterium tuberculosis. Dissertation, Stellenbosch University

9. Du Plessis A (2016) Functionalized Polymer Nanofibrous Substrates as Capturing Platforms for Mycobacteria. Dissertation, Stellenbosch University

10. Fortuin L (2015) Modified chitosan nano-substrates for mycobacterial capture. Dissertation, Stellenbosch University

11. Wang N, Zhu L, Wang D, Wang M, Lin Z, Tang H (2010) Sonoassisted preparation of highly-efficient peroxidase-like $\mathrm{Fe}_{3} \mathrm{O}_{4}$ magnetic nanoparticles for catalytic removal of organic pollutants with $\mathrm{H}_{2} \mathrm{O}_{2}$. Ultrason Sonochem 17:526-533

12. Mahmoudi M, Sant S, Wang B, Laurent S, Sen T (2011) Superparamagnetic iron oxide nanoparticles (SPIONs): development, surface modification and applications in chemotherapy. Adv Drug Deliv Rev 63:24-46

13. Cuong ND, Hoa TT, Khieu DQ, Lam TD, Hoa ND, Van Hieu N (2012) Synthesis, characterization, and comparative gas-sensing properties of $\mathrm{Fe}_{2} \mathrm{O}_{3}$ prepared from $\mathrm{Fe}_{3} \mathrm{O}_{4}$ and $\mathrm{Fe}_{3} \mathrm{O}_{4}$-chitosan. J Alloys Compd 523:120-126

14. Dias AMGC, Hussain A, Marcos AS, Roque ACA (2011) A biotechnological perspective on the application of iron oxide magnetic colloids modified with polysaccharides. Biotechnol Adv 29:142-155

15. Chandra A, Turng LS, Li K, Huang HX (2011) Fracture behavior and optical properties of melt compounded semi-transparent polycarbonate (PC)/alumina nanocomposites. Compos Part A Appl Sci Manuf 42:1903-1909

16. Long J, Jiao A, Wei B, Wu Z, Zhang Y, Xu X, Jin Z (2014) A novel method for pullulanase immobilized onto magnetic chitosan/ $\mathrm{Fe}_{3} \mathrm{O}_{4}$ composite nanoparticles by in situ preparation and evaluation of the enzyme stability. Mol Catal B Enzym 109:53-61

17. Lewis KN, Liao R, Guinn KM, Hickey MJ, Smith S, Behr MA, Sherman DR (2003) Deletion of RD1 from Mycobacterium tuberculosis Mimics Bacille Calmette-Guérin Attenuation. J Infect Dis 187:117-123 
18. Smit M (2018) Polymer-coated magnetic nanoparticles and modified polymer nanofibers for the efficient capture of Mycobacterium tuberculosis (Mtb). Dissertation, Stellenbosch University

19. Kumari S, Khan S (2017) Defluoridation technology for drinking water and tea by green synthesized $\mathrm{Fe}_{3} \mathrm{O}_{4} / \mathrm{Al}_{2} \mathrm{O}_{3}$ nanoparticles coated polyurethane foams for rural communities. Sci Rep 7:1-12

20. Unsoy G, Yalcin S, Khodadust R, Gunduz G, Gunduz U (2012) Synthesis optimization and characterization of chitosan coated iron oxide nanoparticles produced for biomedical applications. J Nanoparticle Res 14:1-13

21. Yuwei C, Jianlong W (2011) Preparation and characterization of magnetic chitosan nanoparticles and its application for $\mathrm{Cu}(\mathrm{II})$ removal. Chem Eng J 168:286-292

22. Thangaraj B, Jia Z, Dai L, Liu D, Du W (2016) Effect of silica coating on $\mathrm{Fe}_{3} \mathrm{O}_{4}$ magnetic nanoparticles for lipase immobilization and their application for biodiesel production. Arab J Chem. https://doi.org/10.1016/j.arabjc.2016.09.004

23. Franco Fraguas L, Batista-Viera F, Carlsson J (2004) Preparation of high-density Concanavalin A adsorbent and its use for rapid, high-yield purification of peroxidase from horseradish roots. J Chromatogr B 803:237-241
24. Gyergyek S, Makovec D, Jagodič M, Drofenik M, Schenk K, Jordan O, Kovač J, Dražič G, Hofmann H (2017) Hydrothermal growth of iron oxide NPs with a uniform size distribution for magnetically induced hyperthermia: structural, colloidal and magnetic properties. J Alloys Compd 694:261-271

25. Tischer M, Pradel G, Ohlsen K, Holzgrabe U (2012) Quaternary ammonium salts and their antimicrobial potential: targets or nonspecific interactions? ChemMedChem 7:22-31

26. Crellin PK, Luo C, Morita YS (2013) Metabolism of plasma membrane lipids in mycobacteria and corynebacteria. In: Valenzuela Baez R (ed) Lipid metabolism, IntechOpen, pp 119-148. https:// doi.org/10.5772/52781

27. Sai H, Fu R, Xiang J, Guan Y, Zhang F (2018) Fabrication of elastic silica-bacterial cellulose composite aerogels with nanoscale interpenetrating network by ultrafast evaporative drying. Compos Sci Technol 155:72-80

Publisher's Note Springer Nature remains neutral with regard to jurisdictional claims in published maps and institutional affiliations. 